\title{
Platelet Microbicidal Proteins and Neutrophil Defensin Disrupt the Staphylococcus aureus Cytoplasmic Membrane by Distinct Mechanisms of Action
}

\author{
Michael R. Yeaman, ${ }^{\star \ddagger}$ Arnold S. Bayer, ${ }^{\star \ddagger}$ Su-Pin Koo, ${ }^{\star}$ Wendy Foss, ${ }^{\S}$ and Paul M. Sullam ${ }^{\S}$ \\ *Division of Infectious Diseases, St. John's Cardiovascular Research Center, LAC-Harbor UCLA Medical Center, Torrance, California \\ 90509; ${ }^{\ddagger}$ UCLA School of Medicine, Los Angeles, California 90024; ${ }^{\S}$ Division of Infectious Diseases, Veterans Affairs Medical Center, San

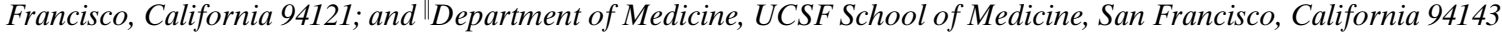

\begin{abstract}
Platelet microbicidal proteins (PMPs) are hypothesized to exert microbicidal effects via cytoplasmic membrane disruption. Transmission electron microscopy demonstrated a temporal association between PMP exposure, damage of the Staphylococcus aureus cytoplasmic membrane ultrastructure, and subsequent cell death. To investigate the mechanisms of action of PMPs leading to membrane damage, we used flow cytometry to compare the effects of two distinct PMPs (thrombin-induced PMP-1 [tPMP-1] or PMP-2) with human neutrophil defensin-1 (hNP-1) on transmembrane potential $(\Delta \psi)$, membrane permeabilization, and killing of S. aureus. Related strains $6850(\Delta \psi-150 \mathrm{mV})$ and JB-1 $(\Delta \psi-100 \mathrm{mV}$; a respiration-deficient menadione auxotroph of 6850) were used to assess the influence of $\Delta \psi$ on peptide microbicidal effects. Propidium iodide (PI) uptake was used to detect membrane permeabilization, retention of 3,3'-dipentyloxacarbocyanine $\left(\mathrm{DiOC}_{5}\right)$ was used to monitor membrane depolarization $(\Delta \psi)$, and quantitative culture or acridine orange accumulation was used to measure viability. PMP-2 rapidly depolarized and permeabilized strain 6850 , with the extent of permeabilization inversely related to $\mathrm{pH}$. tPMP-1 failed to depolarize strain 6850 , but did permeabilize this strain in a manner directly related to $\mathrm{pH}$. Depolarization, permeabilization, and killing of strain JB-1 due to PMPs were significantly less than in strain 6850. Growth in menadione reconstituted $\Delta \psi$ of JB-1 to a level equivalent to 6850 , and was associated with greater depolarization due to PMP-2, but not tPMP-1. Reconstitution of $\Delta \psi$ also enhanced permeabilization and killing of JB-1 due to tPMP-1 or PMP-2. Both PMP-2 and tPMP-1 caused significant reductions in viability of strain 6850. In contrast to tPMP-1 or PMP-2, defensin hNP-1 depolarized, permeabilized, and killed both strains 6850 and JB-1 equally, and in a manner directly related to $\mathrm{pH}$. Collectively, these data indicate that membrane dysfunction and cell death due to tPMP-1, PMP-2, or hNP-1 likely involve different mechanisms. These findings may also reveal new insights into the microbicidal ac-
\end{abstract}

This study was presented in part as abstract A-104 at the 97th Meeting of the American Society for Microbiology, Miami, FL, 4-8 May 1997.

Address correspondence to Dr. Michael R. Yeaman, Division of Infectious Diseases, LAC-UCLA Medical Center, RB-2, 1000 West Carson Street, Torrance, CA 90509. FAX: 310-782-2016; E-mail: yeaman@afp76.humc.edu

Received for publication 6 May 1997 and accepted in revised form 29 October 1997.

The Journal of Clinical Investigation

Volume 101, Number 1, January 1998, 178-187

http://www.jci.org tivities versus mammalian cell toxicities of antimicrobial peptides. (J. Clin. Invest. 1998. 101:178-187.) Key words: platelet • host defense $\bullet$ antimicrobial peptide $\bullet$ microbicidal $\bullet$ transmembrane potential

\section{Introduction}

Recent evidence from our laboratory and others supports the concept that platelets are integral to antimicrobial host defense. A group of small, cationic, proteins with potent microbicidal activity has been isolated recently from rabbit platelets $(1,2)$. These platelet components have been termed platelet microbicidal proteins (PMPs) $)^{1}(1,2)$. Similar microbicidal proteins have also been isolated from human platelets $(3,4)$.

A body of data now exists to suggest that PMPs contribute to the antimicrobial host defense properties of platelets. For example, PMPs have been shown to exert rapid and potent in vitro microbicidal effects against a broad spectrum of microbial pathogens that commonly invade the bloodstream $(1,5$, 6). In addition, thrombin-induced PMP-1 (tPMP-1) is released by rabbit platelets exposed to thrombin under physiological conditions in vitro $(1,2)$. Thrombin is generated after tissue factor release by endothelial cells or monocytes at sites of endovascular damage or microbial colonization (7-9). Furthermore, we have demonstrated recently that PMPs $1-3$ are released from platelets aggregated by staphylococcal cells or stimulated with purified Staphylococcus aureus $\alpha$-toxin (10, 11). Thus, PMPs are likely released at sites of endovascular colonization either by direct platelet activation by microbes or via thrombin production stemming from endothelial cell injury, where they may act to limit infection.

Relevant to these findings are recent studies which have shown that the staphylocidal action of tPMP-1 is retained in serum, and under conditions of temperature, $\mathrm{pH}$, and tonicity which likely exist at sites of endovascular infection $(12,13)$. We have also found that in vitro susceptibility of viridans streptococci, staphylococci, and Candida albicans to tPMP-1 is inversely correlated with virulence in experimental animal models of endovascular infection as compared with genetically related, tPMP-1-resistant counterpart strains (14-16). These recent observations further substantiate the hypothesis that PMPs are likely key components of initial antimicrobial host defense.

Several lines of evidence suggest that the mechanisms of

1. Abbreviations used in this paper: $\Delta \psi$, transmembrane potential; AO, acridine orange; AU-PAGE, acid-urea PAGE; DiOC $_{5}, 3,3^{\prime}$-dipentyloxacarbocyanine; GENT, gentamicin sulfate; hNP-1, human neutrophil defensin-1; MCF, mean channel fluorescence; MVAB, Michaelis veronal-acetate buffer; PI, propidium iodide; PMP, platelet microbicidal protein; PRO, protamine sulfate; TEM, transmission electron microscopy; tPMP-1, thrombin-induced PMP-1. 
PMP antimicrobial action involve targeting and disruption of the microbial cell membrane. For instance, preliminary ultrastructural data indicated that tPMP-1 causes rapid and extensive damage of the staphylococcal membrane, generally followed by nonlytic cell death (17). In addition, recent studies indicate that membrane-stabilizing agents such as dextrans diminish the bactericidal effects of PMPs on staphylococci in vitro (13). Moreover, protoplasts derived from tPMP-1-resistant staphylococci are less sensitive to disruption by tPMP-1 than those from tPMP-1-susceptible counterparts (18). Additionally, tPMP-1 permeabilizes artificial planar lipid bilayers in a voltage-dependent manner (18). Finally, we have demonstrated that the staphylocidal activity of tPMP-1 is influenced by, but not solely dependent on, transmembrane electrical potential $(\Delta \psi)$ in $S$. aureus (12). Despite these advances, direct evidence of membrane damage, depolarization, or permeabilization by PMPs has not been demonstrated previously. Thus, our present investigation was designed to examine and compare the consequences of tPMP-1 or PMP-2 exposure with those of other cationic antimicrobial agents on the cytoplasmic membranes of related staphylococcal strains which differ in baseline $\Delta \psi$.

\section{Methods}

Microorganisms. S. aureus ATCC 27217 (502Ai (American Type Culture Collection, Rockville, MD)) is a well-characterized laboratory strain used in previous studies examining antimicrobial peptide activities (2). S. aureus strains 6850 and JB-1 have also been characterized previously $(12,19)$. This latter genetically related strain pair was obtained from Dr. Richard Proctor (University of Wisconsin, Madison, WI). In brief, strain 6850 is a prototrophic and virulent clinical isolate. JB-1 is a stable, respiration-deficient menadione auxotroph derived from parental strain 6850. As compared with strain 6850 , JB-1 exhibits a significantly lower $\Delta \psi(-100 \mathrm{mV}$ vs. $-150 \mathrm{mV}$ of 6850), a reduced growth rate, and resistance to aminoglycoside antibiotics $(12,19)$. In addition, 6850 and JB-1 have been shown previously to exhibit differential susceptibility to the bactericidal action of tPMP-1 (6850, susceptible; JB-1, resistant) (12). Bacillus subtilis strain ATCC 6633, highly susceptible to tPMP-1, was used to standardize bioactivity of purified tPMP-1 preparations (1). All test organisms were cultured to logarithmic phase at $37^{\circ} \mathrm{C}$ in brain-heart infusion broth (Difco Laboratories, Detroit, $\mathrm{MI}$ ), harvested by centrifugation, washed twice in PBS ( $\mathrm{pH} 7.2)$, and quantified by spectrophotometry $(\lambda=600 \mathrm{~nm})$. In some studies, S. aureus strains 6850 and JB-1 were cultured to logarithmic phase in medium containing menadione (1 $\mu \mathrm{g} / \mathrm{ml}$, in darkness; Sigma Chemical Co., St. Louis, MO), which restores JB-1 $\Delta \psi$ to a level equivalent to parental strain $6850(12,18,19)$.

Acid-urea PAGE ( $A U$-PAGE). Gel filtration fractions and RPHPLC-purified peptides (as described below) were analyzed by AUPAGE using previously described methods $(20,21)$.

PMPs. tPMP-1 and PMP-2 were purified as previously described (2, 20, 21). tPMP-1 and PMP-2 represent different types of PMPs recoverable from thrombin-stimulated or acid-extracted rabbit platelets, respectively. For tPMP-1, platelets were isolated from the whole blood of New Zealand White rabbits, washed in Tyrode's solution ( $\mathrm{pH}$ 7.2; Sigma Chemical Co.), enumerated by spectrophotometry $(\lambda=600 \mathrm{~nm})$, and resuspended in Eagle's MEM (pH 7.2; Irvine Scientific, Santa Ana, CA) to a concentration of $5 \times 10^{8} / \mathrm{ml}$. Preparations enriched in tPMP-1 were subsequently produced from washed platelet suspensions by stimulation with bovine-derived thrombin ( $1 \mathrm{U} / \mathrm{ml}, 37^{\circ} \mathrm{C}, 30 \mathrm{~min}$; Sigma Chemical Co.) in the presence of $0.2 \mathrm{M}$ $\mathrm{CaCl}_{2}$. Platelets were removed by centrifugation, and the supernatant containing tPMP-1 was recovered and lyophilized. For PMP-2, rabbit platelets were isolated, washed, and enumerated as above. Aliquots containing $5 \times 10^{8}$ platelets were sedimented $(1,200 \mathrm{~g}, 10 \mathrm{~min}$ at $20^{\circ} \mathrm{C}$ ), suspended in $6 \mathrm{vol}$ of ice cold $30 \%$ ( $\mathrm{vol} / \mathrm{vol}$ ) acetic acid, and stirred on melting ice for $18 \mathrm{~h}$. The resulting suspension was centrifuged at $18,000 \mathrm{~g}$ for $30 \mathrm{~min}$ at $4^{\circ} \mathrm{C}$, and the supernatant was lyophilized.

Lyophylates of either the tPMP-1 or PMP-2 crude preparations were dissolved in $15 \mathrm{ml} \mathrm{30 \%} \mathrm{acetic} \mathrm{acid,} \mathrm{clarified} \mathrm{by} \mathrm{centrifugation} \mathrm{at}$ $18,000 \mathrm{~g}$ for $10 \mathrm{~min}$ at $4^{\circ} \mathrm{C}$, and fractionated by gel filtration (Bio-Gel P-60; BioRad Laboratories, Hercules, CA). The column was developed at $20^{\circ} \mathrm{C}$ with $30 \%$ acetic acid at $30 \mathrm{ml} / \mathrm{h}$, and the eluent was monitored continuously at $280 \mathrm{~nm}$. Fractions containing antimicrobial activity and protein bands consistent with tPMP-1 or PMP-2 (on AU-PAGE, above) were pooled, concentrated by centrifugal vacuum evaporation (Speed Vac; Savant Instruments, Farmingdale, NY), and diluted in $2 \mathrm{ml}$ of $5 \%$ acetic acid. Peptides (tPMP-1 or PMP-2) were purified from respective fractions by RP-HPLC performed using a $0.46 \times 25 \mathrm{~cm}$ C- 18 column (Vydac; The Separations Group, Hesperia, CA) and developed with water/acetonitrile gradients containing $0.1 \%$ TFA $(2,20,21)$. Homogeneities of purified PMPs were determined by analytical RP-HPLC, and confirmed by AU-PAGE. Purified PMPs were lyophilized, resuspended in sterile $0.01 \%$ acetic acid, and stored until use at $-70^{\circ} \mathrm{C}$.

Bioactivity of PMP preparations. Antimicrobial bioactivities of purified PMPs were confirmed using previously described methods $(1,6)$. Bioassays were performed using B. subtilis ATCC 6633 (1) or S. aureus ATCC 27217 (2), indicator organisms sensitive to the bactericidal action of tPMP-1 or PMP-2, respectively. B. subtilis or S. aureus was added to microtiter wells containing either tPMP-1 or PMP-2 to achieve final inocula of $10^{3} \mathrm{CFU} / \mathrm{ml}$ per well and peptide dilutions ranging from 1:1 to 1:1024 (final well volume $=200 \mu \mathrm{l}$ ). After $30 \mathrm{~min}$ of incubation at $37^{\circ} \mathrm{C}, 20-\mu \mathrm{l}$ aliquots were removed, diluted into PBS containing $0.01 \%(\mathrm{wt} / \mathrm{vol}$ ) sodium polyanethol sulfonate (to inhibit further PMP-induced killing; Sigma Chemical Co.), and quantitatively cultured on $6.6 \%$ sheep blood agar. PMP bioactivity $(\mathrm{U} / \mathrm{ml})$ was defined as the inverse of the highest dilution that exhibited $\geq 95 \%$ lethality versus the respective organisms within $30 \mathrm{~min}$ (1). Purified tPMP-1 or PMP-2 preparations routinely contained $\sim 15$ or $25 \mu \mathrm{g} / \mathrm{ml}$ of protein, and specific activities of $>512$ or $>1,024 \mathrm{U}$ per $\mu \mathrm{g}$, respectively (2).

Comparative cationic antimicrobial agents. For comparison with tPMP-1 or PMP-2, several other cationic antimicrobial agents were assessed for their effects on the cytoplasmic membranes of staphylococci. Human neutrophil defensin-1 (hNP-1; Sigma Chemical Co.) is a small $(3.8 \mathrm{kD})$, cationic microbicidal peptide that has been shown to both depolarize and permeabilize microbial cell membranes (22). Protamine sulfate (PRO; Sigma Chemical Co.) is a cationic protein known to exert antimicrobial activities against staphylococci via $\Delta \psi$ dependent membrane perturbation $(13,16,23)$. Additionally, susceptibility of $S$. aureus strains to PRO parallels that of tPMP-1 (12). Gentamicin sulfate (GENT; Sigma Chemical Co.) is a cationic, bactericidal aminoglycoside antibiotic with a mechanism of action that requires an intact $\Delta \psi$, but does not cause membrane permeabilization (24). $S$. aureus strains 6850 or JB-1 have been demonstrated previously to exhibit susceptibility or resistance to PRO and GENT, respectively, in vitro (12). For studies of staphylococcal $\Delta \psi$, the ionophore valinomycin (Sigma Chemical Co.) was used as a positive control for depolarization (25). Cells were exposed to ethanol (70\% HPLC grade; Sigma Chemical Co.) as a positive control for membrane permeabilization $(25,26)$.

Transmission electron microscopy (TEM). TEM was used to examine the ultrastructural effects of PMPs on staphylococcal cells in vitro. The ultrastructural effects of hNP-1 were not studied presently, as these data have been reported recently in detail (27). S. aureus strains were cultured to midlogarithmic phase and exposed to PMPs as above. Cells were then pelleted, washed, and fixed for $8 \mathrm{~h}$ at $24^{\circ} \mathrm{C}$ in $0.5 \%(\mathrm{wt} / \mathrm{vol})$ osmium tetroxide (Sigma Chemical Co.) prepared in Michaelis veronal-acetate buffer (MVAB; $0.24 \mathrm{M}$ sodium acetate, $0.14 \mathrm{M}$ sodium veronal-barbital, and $0.58 \mathrm{M}$ sodium chloride, $\mathrm{pH} 6.1$, 
containing $0.05 \%$ [wt/vol] tryptone broth; Difco Laboratories). The fixative was refreshed at 15, 30, and $90 \mathrm{~min}$. Fixed cells were washed and embedded in $0.5 \mathrm{ml}$ of $2 \%$ (wt/vol) molecular-grade agarose (Fisher Scientific Co., Fair Lawn, NJ) prepared in MVAB warmed to $43^{\circ} \mathrm{C}$. Agarose blocks were sectioned $\left(1-\mathrm{mm}^{3}\right.$ cubes) and stained with $1 \%$ uranyl acetate (Aldrich Chemical Co., Allentown, PA; in MVAB). Stained sections were washed twice in MVAB and postfixed in $1 \%$ osmium tetroxide ( $90 \mathrm{~min}$ in MVAB), followed by two washes in MVAB. Serial dehydration, resin embedding, thin sectioning, gridmounting (400 mesh, copper), and poststaining with uranyl acetate and lead citrate (each $1 \%$ in MVAB) were performed using routine TEM techniques. Thin sections prepared as above were examined with a JEOL 100B transmission electron microscope using an accelerating voltage of $80 \mathrm{kV}$.

Spectrophotometry. Assessment of staphylococcal cell lysis was performed using visible light spectrophotometry (Spectronic 401; Spectronic Instruments, Rochester, NY). Optical densities (wavelength, $420 \mathrm{~nm}\left[\mathrm{OD}_{420}\right]$ ) of $S$. aureus suspensions exposed to PMPs as above were determined at selected times ranging from 0 to $120 \mathrm{~min}$, and compared with control cells. Decreases in optical density were interpreted to represent cell lysis.

Flow cytometry. Effects of the various cationic agents above on staphylococcal membranes were assessed by flow cytometry using a FACScan ${ }^{\circledR}$ instrument (Becton Dickinson, San Jose, CA). Propidium iodide (PI; Molecular Probes, Eugene, OR) and acridine orange (AO; Molecular Probes) were excited at $488 \mathrm{~nm}$ with an argon laser, and the resulting fluorescence emission was collected through a $\geq 620 \mathrm{~nm}$ long pass filter. The cyanine dye 3,3'-dipentyloxacarbocyanine ( $\mathrm{DiOC}_{5}$; Molecular Probes) was excited at $488 \mathrm{~nm}$ and the emitted light was collected through a $525 \pm 25 \mathrm{~nm}$ band pass filter. Flow cytometry studies were performed at $20^{\circ} \mathrm{C}$ in potassium-containing MEM $\left(\mathrm{K}^{+} \mathrm{MEM}\right.$; no phenol red, pH 7.2; Sigma Chemical Co.) (25). Forward light scatter data were collected for each sample to assess cell size and to ensure that changes in fluorescence were not artifacts of cell clumping. For each analysis, the fluorescence of 10,000 cells was acquired and plotted against forward light scatter (flow rate, 200 cells/s).

Exposure of $S$. aureus to cationic agents before flow cytometry. After growth in the presence or absence of menadione, logarithmic phase staphylococcal cells were exposed to different cationic antimicrobials before flow cytometric analysis. Organisms were independently exposed to the following agents in $\mathrm{K}^{+} \mathrm{MEM}$ adjusted to $\mathrm{pH} 5.5$ (with $\mathrm{HCl}$ ) or 7.2 for predetermined times (range $0-120 \mathrm{~min}$ ) at $37^{\circ} \mathrm{C}$ before analysis of $\Delta \psi$, membrane permeability, or cell viability: tPMP-1 (20 $\mu \mathrm{g} / \mathrm{ml})$; PMP-2 (10 $\mu \mathrm{g} / \mathrm{ml}) ;$ hNP-1 (10 $\mu \mathrm{g} / \mathrm{ml})$; GENT (10 $\mu \mathrm{g} / \mathrm{ml})$; or PRO $(150 \mu \mathrm{g} / \mathrm{ml})$. These levels represent staphylocidal concentrations for each agent. Control cells were exposed in parallel to either $\mathrm{K}^{+} \mathrm{MEM}$ alone, valinomycin alone $(5 \mu \mathrm{g} / \mathrm{ml})$, or ethanol alone $(70 \% \mathrm{vol} / \mathrm{vol})$.

Analysis of membrane depolarization. $\mathrm{DiOC}_{5}$ is a charged lipophilic dye which partitions into the cytoplasm, and is dependent on intact $\Delta \psi$ for intracellular retention (25). Organisms cultured in the presence or absence of menadione were pelleted by centrifugation, washed in PBS, resuspended to a concentration of $5 \times 10^{8} \mathrm{CFU} / \mathrm{ml}$ in $\mathrm{K}^{+} \mathrm{MEM}$ containing an individual cationic agent, and incubated for predetermined times at $37^{\circ} \mathrm{C}$. For analysis of $\Delta \psi$, staphylococci were incubated in darkness for $30 \mathrm{~min}$ at $20^{\circ} \mathrm{C}$ in PBS containing $0.05 \mu \mathrm{M}$ $\mathrm{DiOC}_{5}$ to prelabel the organisms (25). Organisms were pelleted by centrifugation, washed, resuspended, briefly sonicated to ensure singlet cells $\left(60 \mathrm{~Hz}\right.$ for $5 \mathrm{~s}$ at $4^{\circ} \mathrm{C}$; sonifier model 350; Branson, Danbury, $\mathrm{CT}$ ), counted using a hemacytometer, and resuspended in $\mathrm{K}^{+} \mathrm{MEM}$. Flow cytometric analysis of $\Delta \psi$ was performed immediately as described above. Positive control cells exposed to valinomycin, as well as control cells not exposed to any experimental agents, were analyzed for $\mathrm{DiOC}_{5}$ fluorescence in parallel. Reductions in mean $\mathrm{DiOC}_{5}$ fluorescence were interpreted to represent loss of $\mathrm{DiOC}_{5}$, indicating depolarization of the staphylococcal membrane. A minimum of two experiments was performed for each cationic agent to assess depolarization.
Analysis of membrane permeabilization. PI is excluded from cells with normal membrane integrity (25). However, PI enters cells which have increased membrane permeabilization to molecules $\geq 2 \mathrm{~nm}$ in diameter, binds to double-stranded nucleic acids, and can be stimulated to emit intense fluorescence at $>620 \mathrm{~nm}$ (26). S. aureus strains 6850 or JB-1 (cultured with or without menadione) were exposed to the same cationic agents used above for the depolarization assays before assessment of membrane permeability by flow cytometry. Organisms were prepared as above, resuspended to concentrations of $5 \times 10^{8} \mathrm{CFU} / \mathrm{ml}$ in $\mathrm{K}^{+} \mathrm{MEM}$ containing a single cationic agent, and incubated for preselected times (range 0 to $120 \mathrm{~min}$ ) at $37^{\circ} \mathrm{C}$. After exposure, cells were pelleted, washed in fresh $\mathrm{K}^{+} \mathrm{MEM}$, sonicated as above, counted, and resuspended in $\mathrm{K}^{+} \mathrm{MEM}$ containing $20 \mu \mathrm{M}$ PI (26). PI uptake was quantified at preselected times by flow cytometry as described above. Control cells exposed to no agents or ethanol (a positive control for membrane permeabilization) were analyzed for PI uptake in parallel. Increases in mean PI fluorescence were interpreted to indicate increases in staphylococcal membrane permeability. A minimum of two experiments was performed for each cationic agent to assess permeabilization.

Analysis of S. aureus viability. Viability of staphylococcal cells after exposure to cationic agents was determined by quantitative culture and uptake of AO. Aliquots of cells exposed to various cationic agents or controls were removed, serially diluted in PBS containing $0.01 \%$ sodium polyanethol sulfonate as above, plated onto $6.6 \%$ sheep blood agar, and incubated for $24 \mathrm{~h}$ at $37^{\circ} \mathrm{C}$. Colonies were then enumerated and compared with control samples. Results represent mean $\mathrm{CFU} / \mathrm{ml} \pm$ standard error from two or more independent assays, each performed in replicates.

$\mathrm{AO}$ is accumulated within viable bacteria, whereas it is excluded from dead cells (28). In parallel with assays for membrane permeability or $\Delta \psi$, selected cell samples exposed to cationic agents were resuspended in $\mathrm{K}^{+}$MEM containing $10 \mu \mathrm{M}$ AO. Flow cytometry (excitation $488 \mathrm{~nm}$, emission $640 \mathrm{~nm}$ ) was then performed to determine the mean AO fluorescence of cells. Viability was determined from mean AO fluorescence as the proportion of $5 \times 10^{8}$ cells which emitted fluorescence. Viability determinations by quantitative culture were used to confirm quantification of viability determined by AO uptake (above).

Statistical analyses. Each analysis was performed independently a minimum of two times. Differences in mean ( \pm standard error) channel fluorescence between control and experimental cells, or among cells exposed to distinct agents or under varying conditions of $\mathrm{pH}$, were compared using Kruskall-Wallis rank-sum analysis for nonparametric data. Regression analyses were performed using Spearman rank correlation. $P \leq 0.05$ and $r^{2} \geq 0.5$ were considered significant.

\section{Results}

PMPs caused ultrastructural changes in the S. aureus cytoplasmic membrane. $S$. aureus strains exhibited significant ultrastructural damage as assessed by TEM (Fig. 1). Cell damage was principally manifested as a progressive deterioration of the cytoplasmic membrane (Fig. 1, $A-D$ ). Changes in membrane ultrastructure were observed as early as $30 \mathrm{~min}$ of PMP exposure, with substantial damage evident by 90 min of exposure (Fig. 1). It is particularly notable that the staphylococcal cell wall was not significantly affected; correspondingly, PMPs did not typically cause lysis of staphylococcal cells (Fig. 1,D). Similar effects were observed with either tPMP-1 (Fig. 1) or PMP-2 (data not shown), and increased with greater PMP exposure time ranging from 30 to $120 \mathrm{~min}$ (Fig. $1, A-D$ ). Ultrastructural consequences of hNP-1 upon $S$. aureus paralleling those presently observed due to PMPs have been demonstrated previously (27). 


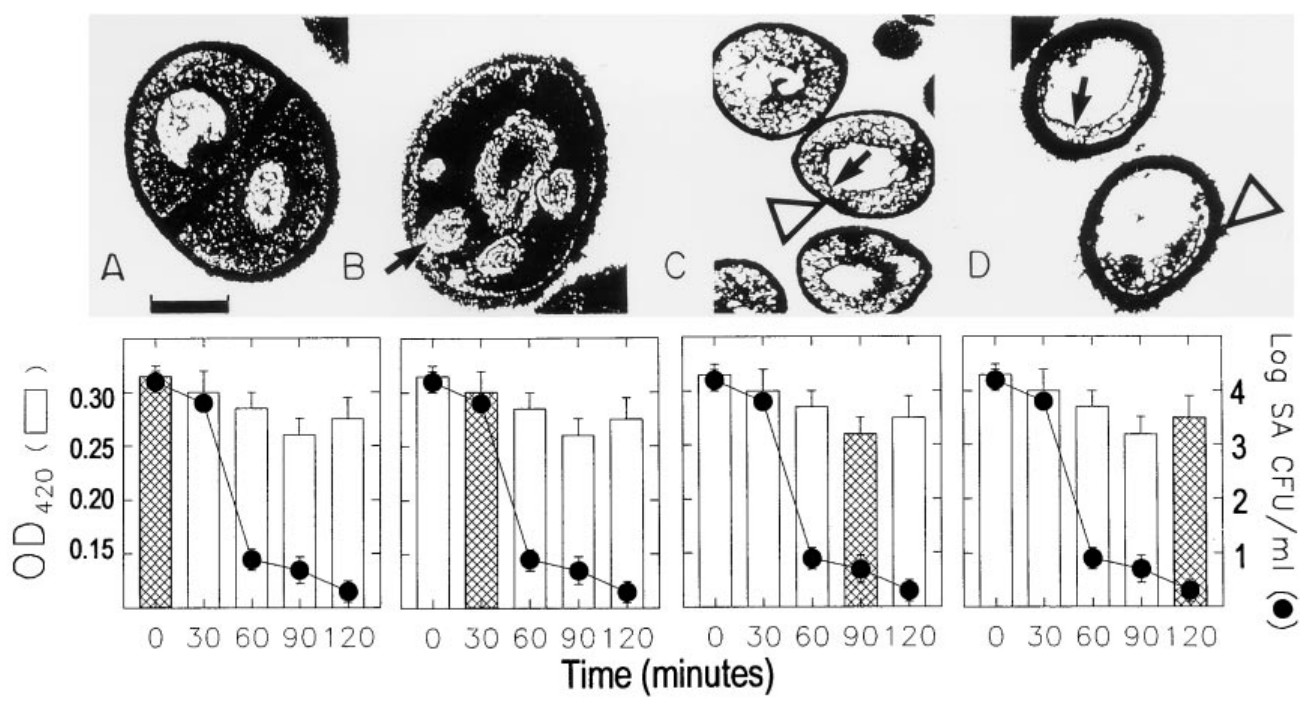

Figure 1. Summary of the effects of tPMP-1 on S. aureus ultrastructure. Strain 502A $\left(10^{5} \mathrm{CFU} /\right.$ $\mathrm{ml})$ was exposed to tPMP-1 $(5 \mu \mathrm{g} / \mathrm{ml})$ in MEM as described in Methods. At selected time points, suspensions were assessed for optical density, and samples were removed for quantitative culture and TEM as described in Methods. Histograms or closed circles represent mean optical densities or viabilities from a minimum of two independent experiments. Hatched histograms denote time points corresponding to TEM micrographs shown in $A-D$. Similar effects have been observed for SA 6850 and JB-1 (not shown). Note progressive damage to the cytoplasmic membrane (arrows), whereas the cell wall remains intact (open arrowheads). Results shown are representative of a minimum of two separate experiments. Bar, $1 \mu \mathrm{m}$.

Flow cytometry quantified $S$. aureus depolarization, permeabilization, and viability. $\mathrm{DiOC}_{5}$ emission corresponded with transmembrane potential $(\Delta \psi)$ in $S$. aureus strains 6850 and JB-1. 6850 and JB-1 strains exposed to buffer alone emitted $\mathrm{DiOC}_{5}$ fluorescence reflecting their difference in baseline $\Delta \psi$ (mean channel fluorescence [MCF] 215.9 \pm 21.9 or $204.7 \pm 17.2$ [6850], vs. $163.9 \pm 16.1$ or $162.4 \pm 14.6$ [JB-1], at $\mathrm{pH} 5.5$ or 7.2 , respectively). As anticipated, exposure to valinomycin caused significant decreases in $\mathrm{DiOC}_{5}$ fluorescence in both strains at both $\mathrm{pH} 5.5$ and 7.2, indicating membrane depolarization had occurred ( $P<0.001$ vs. control; Table I).

$S$. aureus strains 6850 or JB-1 exposed to MEM alone at either $\mathrm{pH} 5.5$ or 7.2 failed to accumulate PI (MCF, $4.8 \pm 2.9$ or $4.2 \pm 2.1$ [6850], respectively, or $5.8 \pm 3.3$ or $8.2 \pm 4.0$ [JB-1], respectively). As expected, exposure of either strain to ethanol caused significant uptake of PI at both $\mathrm{pH} 5.5$ and 7.5, indicating membrane permeabilization had occurred $(P<0.001$ vs. controls; Table I). Likewise, AO fluorescence at $\mathrm{pH} 5.5$ or 7.2 corresponded with viability of strains as determined by quantitative culture (Table I).
PMP-2 and tPMP-1 caused differential membrane depolarization of strain 6850. Exposure of strain 6850 to PMP-2 at either $\mathrm{pH} 5.5$ or 7.2 resulted in significant depolarization as compared with control cells (Table I). For example, strain 6850 exhibited a decrease in $\mathrm{DiOC}_{5}$ emission of $-122.7 \pm 6.4 \mathrm{MCF}$ (a 43\% loss) as compared with control after exposure for 120 min to PMP-2 at pH $5.5(P<0.05$; Table I). Exposure of 6850 to PMP-2 at pH 7.2 caused depolarization that was not significantly different from that seen at pH 5.5 ( $P>0.05$; Fig. 2$)$. In addition, there were no significant differences in the effects of the different concentrations of PMP-2 studied on depolarization in strain 6850 (Fig. 2). Depolarization associated with 30 min of PMP-2 exposure was not significantly different from that seen after 60 min of exposure $(P>0.05$; Fig. 2$)$. Thus, PMP-2 depolarization of 6850 was relatively independent of exposure $\mathrm{pH}$, time, or peptide concentration. Similar to PMP-2, exposures to the comparative agents hNP-1, GENT, or PRO $(\mathrm{pH}$ 7.2) resulted in significant depolarization of strain 6850 (Table I). In contrast, tPMP-1 failed to depolarize strain 6850 at pH 5.5 (data not shown) or pH 7.2 (Table I).

Table I. Relationship among Deplorization, Permeabilization, and Viability in S. aureus*

\begin{tabular}{|c|c|c|c|c|c|c|}
\hline \multirow[b]{2}{*}{ Exposure } & \multicolumn{3}{|c|}{ SA 6850} & \multicolumn{3}{|c|}{ SA JB-1 } \\
\hline & $\begin{array}{c}\Delta \mathrm{DiOC}_{5} \\
\text { retention } \\
(\Delta \psi)\end{array}$ & $\begin{array}{l}\Delta \text { PI uptake } e^{\ddagger} \\
(\text { permeability) }\end{array}$ & $\begin{array}{c}\Delta \log C F U / \mathrm{ml}^{\S} \\
\text { (viability) }\end{array}$ & $\begin{array}{c}\Delta \mathrm{DiOC}_{5} \\
\text { retention }(\Delta \psi)\end{array}$ & $\begin{array}{c}\Delta \text { PI uptake } \\
\text { (permeability) }\end{array}$ & $\begin{array}{c}\Delta \mathrm{Log} \text { CFU/ml } \\
\text { (viability) }\end{array}$ \\
\hline $\mathrm{EtOH}$ & $-77.0 \pm 9.2^{\|}$ & $151.2 \pm 12.8^{\|}$ & $-4.0 \pm 0.9^{\|}$ & $-65.9 \pm 4.4^{\|}$ & $168.3 \pm 22.2^{\|}$ & $-4.1 \pm 1.0^{\|}$ \\
\hline PMP-2 & $-122.7 \pm 6.4 \|$ & $198.6 \pm 16.3^{\|}$ & $-2.9 \pm 0.4 \|$ & $-83.5 \pm 10.3^{\| \pi}$ & $89.4 \pm 12.6^{\| t / \pi}$ & $-1.8 \pm 0.6^{\| \pi}$ \\
\hline tPMP-1 & $18.5 \pm 7.3$ & $164.8 \pm 11.6^{\|}$ & $-1.4 \pm 0.6^{\|}$ & $15.0 \pm 7.1$ & $80.6 \pm 16.1^{\| \pi \mathrm{II}}$ & $-0.8 \pm 0.3^{\|}$ \\
\hline NP-1 & $-122.5 \pm 17.4 \|$ & $128.2 \pm 8.6^{\|}$ & $-2.3 \pm 0.5^{\|}$ & $-108.2 \pm 5.2^{\|}$ & $102.9 \pm 3.4^{\|}$ & $-2.1 \pm 0.7 \|$ \\
\hline Gentamicin & $-108.3 \pm 9.1 \|$ & $0.5 \pm 5.4$ & $-0.6 \pm 0.2$ & $-42.2 \pm 10.8^{\| \pi}$ & $2.2 \pm 2.0$ & $-0.6 \pm 0.4$ \\
\hline Protamine & $-141.8 \pm 11.0^{\|}$ & $17.3 \pm 7.7$ & $-1.3 \pm 0.5^{\|}$ & $-17.1 \pm 9.9^{\pi}$ & $3.9 \pm 7.5$ & $-0.3 \pm 0.2^{\| \pi}$ \\
\hline Valinomycin & $-144.1 \pm 16.5^{\|}$ & $\mathrm{ND} * *$ & $-1.2 \pm 0.3^{\|}$ & $-98.5 \pm 16.3^{\| \pi}$ & ND & $-0.5 \pm 0.3^{\mathbb{I}}$ \\
\hline
\end{tabular}

$* \mathrm{MCF}$, minimum $n=2$; PMP-2 exposure performed at $\mathrm{pH} 5.5$; all others performed at $\mathrm{pH} 7.2$ (see text for concentrations). ${ }^{\ddagger} \mathrm{Change}$ in $\mathrm{MCF}$ versus control as determined by flow cytometry. ${ }^{\S} \mathrm{Logarithm}_{10} \mathrm{CFU} / \mathrm{ml}$ determined at $60 \mathrm{~min}$ of exposure by quantitative culture; selected data corroborated by AO fluorescence. ** Not determined. Significantly different $(P<0.05)$ from: ${ }^{*}$ control; ${ }^{\mathrm{q}}$ strain 6850. 

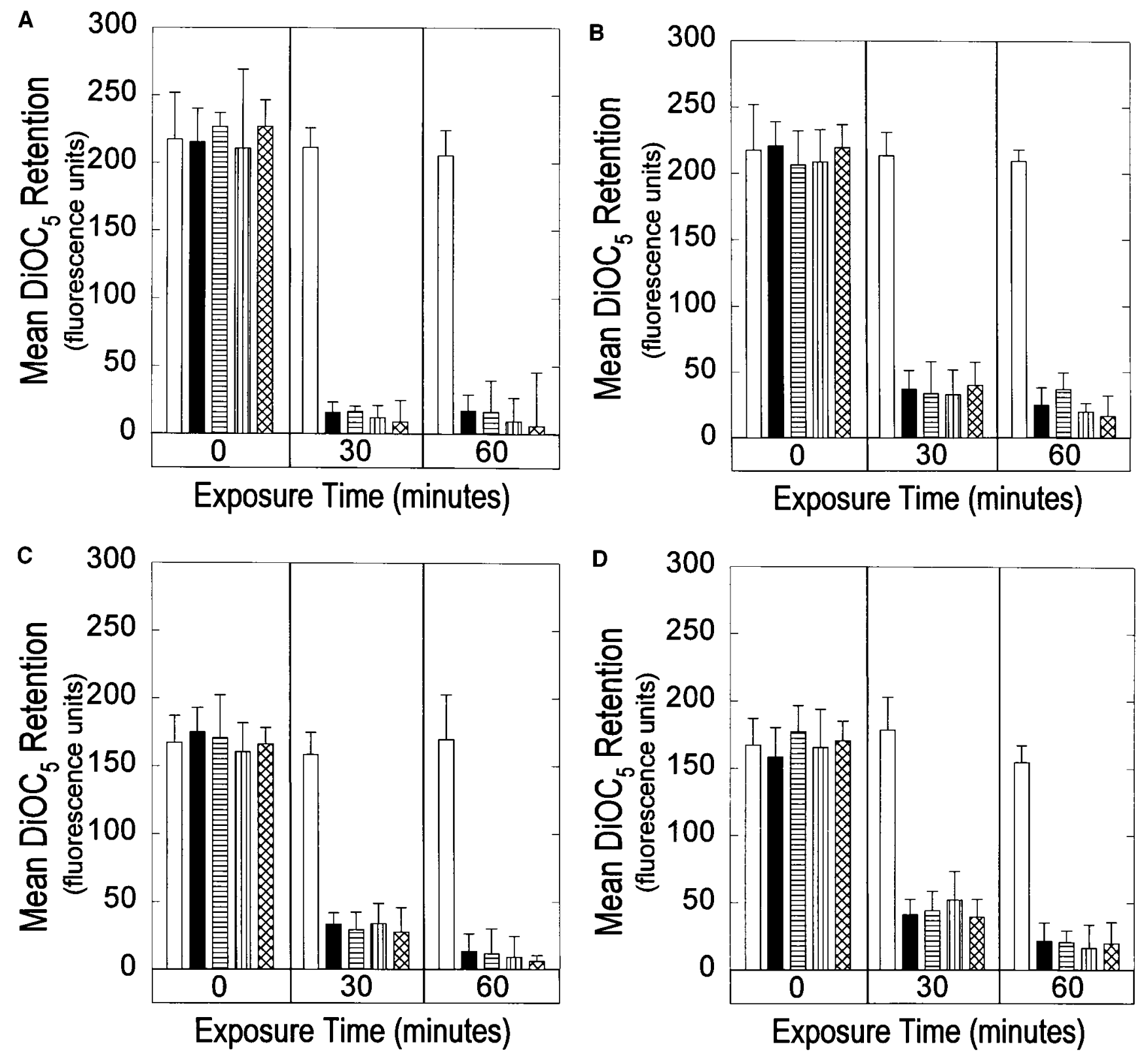

Figure 2. Depolarization of staphylococcal cytoplasmic membranes due to PMP-2. Strain 6850 was exposed to $10 \mu \mathrm{g}$ PMP-2/ml for times and concentrations indicated at either pH $5.5(A)$ or pH 7.2 $(B)$. Similarly, strain JB-1 (without prior menadione culture) was exposed to PMP-2 as indicated at either $\mathrm{pH} 5.5(C)$ or $\mathrm{pH} 7.2(D)$. Histograms represent $\mathrm{DiOC}_{5} \mathrm{MCF}$ (fluorescence units) \pm standard error of the mean (bars) of two or more independent experiments. White bars, control; black bars, $1 \mu \mathrm{g} / \mathrm{ml}$; horizontally striped bars, $5 \mu \mathrm{g} / \mathrm{ml}$; vertically striped bars, $10 \mu \mathrm{g} / \mathrm{ml}$; hatched bars, $20 \mu \mathrm{g} / \mathrm{ml}$.

PMP-2 and tPMP-1 caused membrane permeabilization of strain 6850. PMP-2 produced rapid and significant permeabilization of strain 6850. For example, PMP-2 caused a significant increase in permeability of 6850 at $\mathrm{pH} 5.5$ as compared with control cells (Fig. 3 and Table I). Permeabilization due to PMP-2 at pH 7.2 occurred, but was less extensive, and produced a notable bimodal distribution in strain 6850 (Figs. 3 and 4 , and Table I). Thus, PMP-2 permeabilization of 6850 was inversely correlated with $\mathrm{pH}$. Furthermore, permeabilization of 6850 by PMP-2 was dependent on exposure time and peptide concentration at either $\mathrm{pH} 5.5$ or 7.2 (Fig. 5).
tPMP-1 caused membrane permeabilization of strain 6850 which was less than PMP-2, and correlated directly with $\mathrm{pH}$. Thus, exposure of strain 6850 to tPMP-1 at $\mathrm{pH} 7.2$ produced a greater increase in permeabilization $(P<0.05$ vs. controls; Fig. 3 and Table I) than occurred at pH $5.5(P>0.05$; Fig. 3). Similar to PMP-2 at $\mathrm{pH}$ 7.2, tPMP-1 exposure at $\mathrm{pH} 5.5$ caused a bimodal distribution in PI uptake, corresponding with overall reduced permeabilization (Fig. 4).

Like tPMP-1, hNP-1 caused membrane permeabilization of strain 6850 which was significantly greater at $\mathrm{pH} 7.2$ as compared with $\mathrm{pH} 5.5(P<0.01$; Fig. 3$)$, and produced a bimodal 


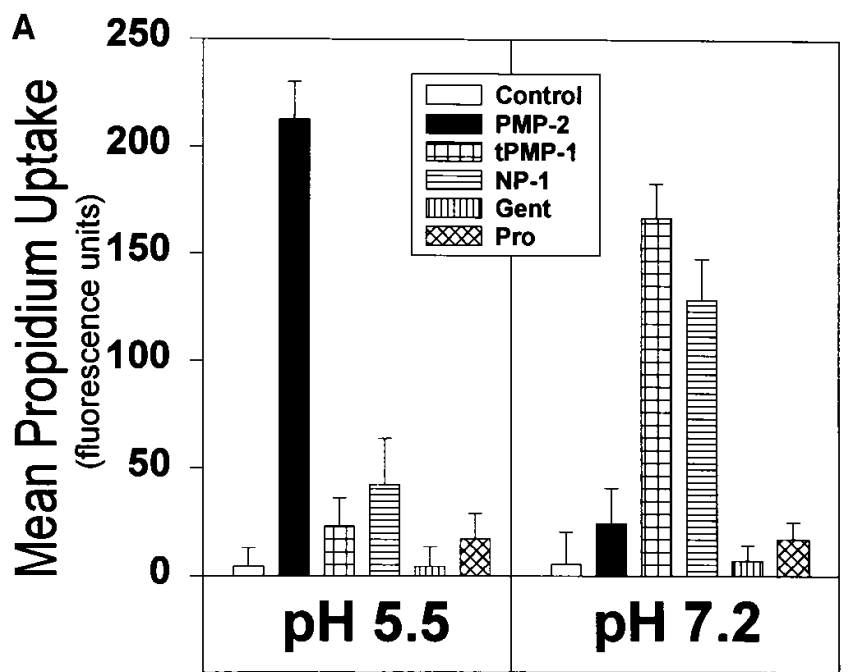

S. aureus 6850 Exposure

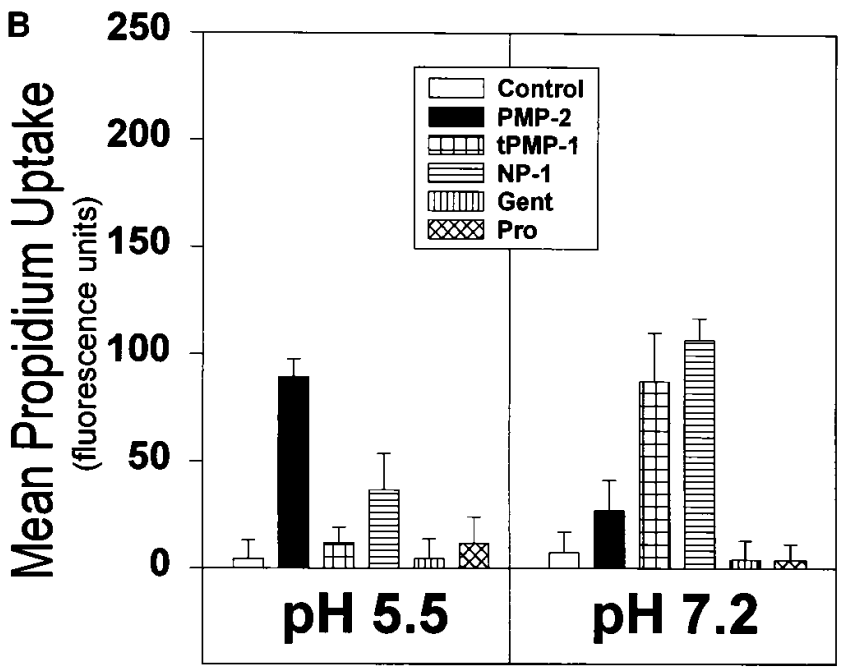

\section{S. aureus JB-1 Exposure}

Figure 3. Influence of $\mathrm{pH}$ on staphylococcal membrane permeabilization by various cationic antimicrobial agents. Strains $6850(A)$ or JB-1 $(B)$ were exposed to agents at $\mathrm{pH} 5.5$ or 7.2 as indicated for 60 min at the following concentrations as described in the text: PMP-2 (10 $\mu \mathrm{g} / \mathrm{ml})$; tPMP-1 $(20 \mu \mathrm{g} / \mathrm{ml})$; hNP-1 (10 $\mu \mathrm{g} / \mathrm{ml})$; GENT (10 $\mu \mathrm{g} / \mathrm{ml})$; or PRO $(150 \mu \mathrm{g} / \mathrm{ml})$. Histograms represent PI MCF (fluorescence units) \pm standard error of the mean (bars) of two or more independent experiments.

profile at pH 5.5 (Fig. 4). Neither PRO nor GENT produced significant permeabilization of strain 6850 as compared with controls $(P>0.05$; Table I).

$P M P$-induced membrane perturbation in JB-1 was reduced as compared with 6850. At $\mathrm{pH} 5.5$, depolarization due to PMP-2 was significantly less in strain JB-1 as compared with strain 6850 ( $P<0.01$; Fig. 2). Exposure of JB-1 to PMP-2 at pH 7.2 led to a further reduction in depolarization as compared with pH 5.5 (Fig. 2). Thus, the effects of PMP-2 on depolarization in JB-1 were influenced by $\mathrm{pH}$, but were independent of exposure time or peptide concentration (Fig. 2). As seen in strain
6850, tPMP-1 failed to depolarize strain JB-1 at pH 5.5 (data not shown) or pH 7.2 (Table I). In contrast, hNP-1 (pH 7.2) caused depolarization which was not significantly different in strain JB-1 as compared with $6850(P>0.05$; Table I).

Membrane permeabilization of JB-1 due to PMP-2 was significantly greater at $\mathrm{pH} 5.5$ than at $\mathrm{pH} 7.2(P<0.01$; Fig. 3 and Table I). JB-1 permeabilization due to PMP-2 was significantly less than strain 6850 at $\mathrm{pH} 5.5(P<0.01)$, but not significantly different at $\mathrm{pH} 7.2(P>0.05)$. In contrast, tPMP-1 at $\mathrm{pH} 7.2$ caused a significant increase in permeabilization of strain JB-1 as compared with controls $(P<0.05$; Fig. 3 and Table I), but no significant increase at pH $5.5(P>0.05$; Table I). tPMP-1 yielded permeabilization in strain JB-1 which was significantly less than that of 6850 at $\mathrm{pH} 7.2(P<0.05$; Table I), but not different at pH $5.5(P>0.05)$. Thus, tPMP-1 caused permeabilization which corresponded directly with $\mathrm{pH}$. Like 6850 , per-
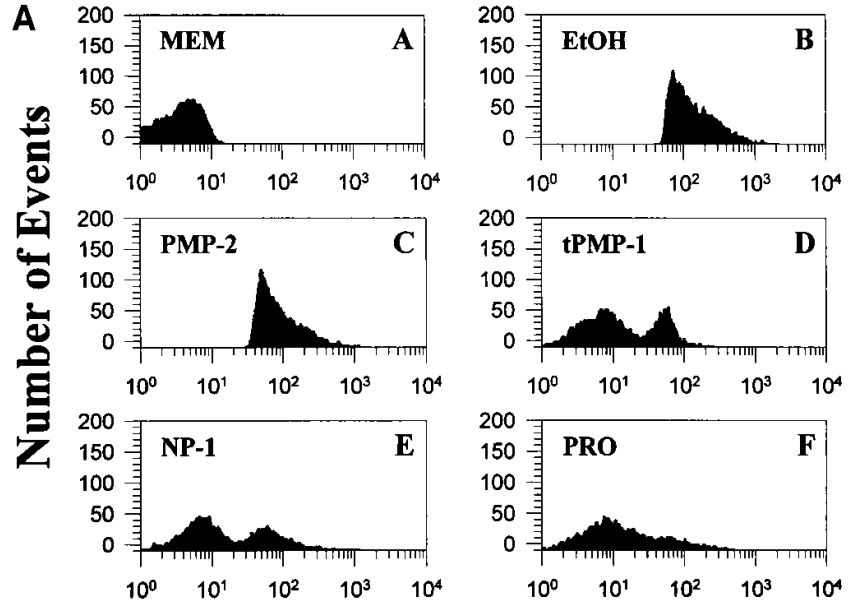

\section{$\log _{10}$ Fluorescence}

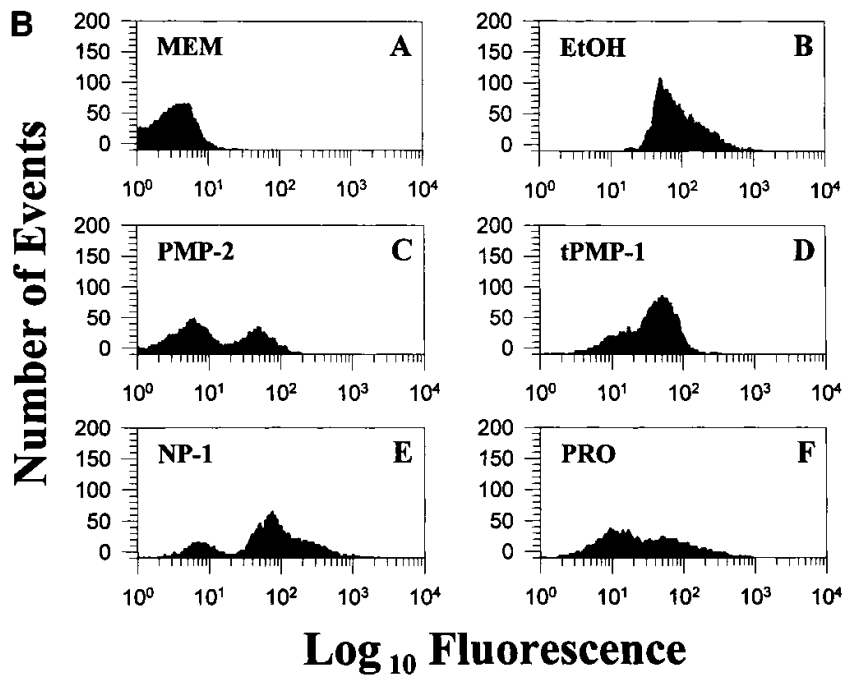

Figure 4. Fluorescence profiles of strain 6850 cytoplasmic membrane permeabilization due to various agents at $\mathrm{pH} 5.5(A)$ or $\mathrm{pH} 7.2(B)$. Cationic agent exposure conditions were identical to those listed in Fig. 3. Profile distribution represents a total of 10,000 individual PI fluorescence events captured within $1 \mathrm{~min}$. Note bimodal distributions for tPMP-1 and hNP-1 at pH 5.5, and PMP-2 at $\mathrm{pH}$ 7.2. 


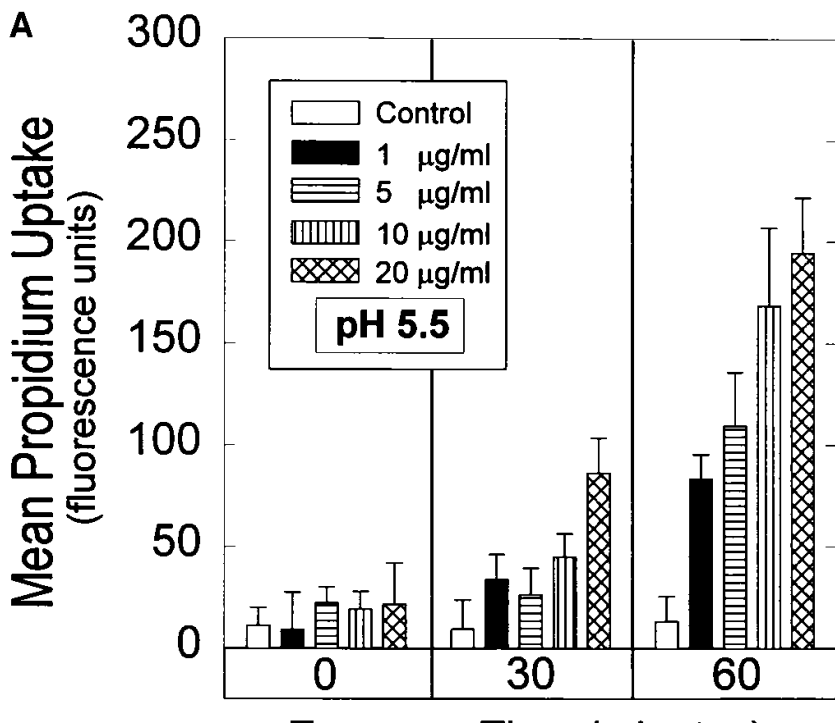

Exposure Time (minutes)

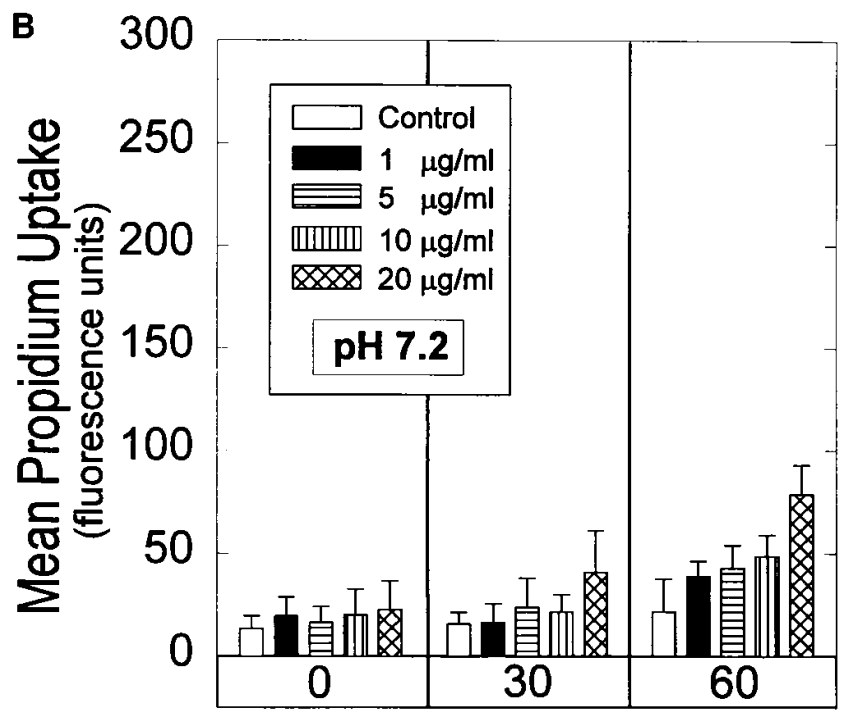

Exposure Time (minutes)

Figure 5. Relationship among PMP-2 exposure time, concentration, and $\mathrm{pH}$ on membrane permeabilization of strain 6850. Organisms were exposed to purified PMP-2 for times and at concentrations indicated at either pH $5.5(A)$ or $\mathrm{pH} 7.2(B)$. Histograms represent PI MCF (fluorescence units) \pm standard error of the mean (bars) of two or more independent experiments.

meabilization of JB-1 due to tPMP-1 or PMP-2 was exposure time and concentration dependent (data not shown).

Defensin hNP-1 caused permeabilization of strain JB-1 which was significantly greater at $\mathrm{pH} 7.2$ than at $\mathrm{pH} 5.5(P<$ 0.01; Figs. 3 and 4). However, permeabilization of strain JB-1 due to hNP-1 at $\mathrm{pH} 7.2$ was not significantly different from that observed in strain $6850(P>0.05)$. At the concentrations tested, neither PRO nor GENT produced significant increases in membrane permeability of strain JB-1 as compared with controls $(P>0.05$; Figs. 3 and 4 , and Table I).

Reconstitution of $\Delta \psi$ enhanced depolarization, permeabilization, and killing of $J B-1$. In parallel to the above studies, de- polarization, permeabilization, and viability were studied in strain JB-1 after growth in the presence of menadione to reconstitute $\Delta \psi$ to levels equivalent to those in strain 6850. Consistent with previous findings $(12,18)$, menadione restored $\Delta \psi$ of strain JB-1 such that there was no significant difference between $\Delta \psi$ of JB-1 and 6850 as determined by DiOC 5 fluorescence (MCF, 208.6 \pm 17.6 vs. 196.7 \pm 10.1 , respectively, $\mathrm{pH} 7.2$; $P>0.05)$. As a control, growth in menadione did not enhance depolarization, permeabilization, or reduce cell viability in strain 6850 exposed to tPMP-1, PMP-2, or hNP-1 as compared with organisms grown without menadione $(P>0.05$; Table II).

Culture in menadione resulted in significantly greater depolarization, permeabilization, and cell killing of JB-1 due to PMP-2 as compared with cells grown without menadione $(P<$ 0.01; Table II). For example, permeabilization (PI uptake) increased by $96.6 \pm 8.2 \mathrm{MCF}$ in JB-1 cultured without menadione, and 171.6 $\pm 17.1 \mathrm{MCF}$ after growth in menadione $(10 \mu \mathrm{g} /$ ml PMP-2 exposure for $120 \mathrm{~min}, \mathrm{pH} 5.5 ; P<0.05 \mathrm{vs}$. control 5.8 \pm 3.3 ; Table II). PMP-2 staphylocidal activity was also enhanced in JB-1 grown in menadione as compared with controls $(P>0.05$; Table II $)$.

Despite reconstitution of $\Delta \psi$, tPMP-1 did not cause significant depolarization in JB-1 cells cultured in menadione $(P>$ 0.05; Table II). However, menadione-cultured JB-1 cells exhibited a significant increase in permeabilization as compared with cells grown without menadione $(P<0.01$; Table II). Additionally, culture in menadione caused significantly greater reduction in viability of JB-1 exposed to tPMP-1 as compared with cells grown in the absence of menadione $(P<0.01$; Table II). In contrast to the effects observed due to tPMP-1 or PMP-2,

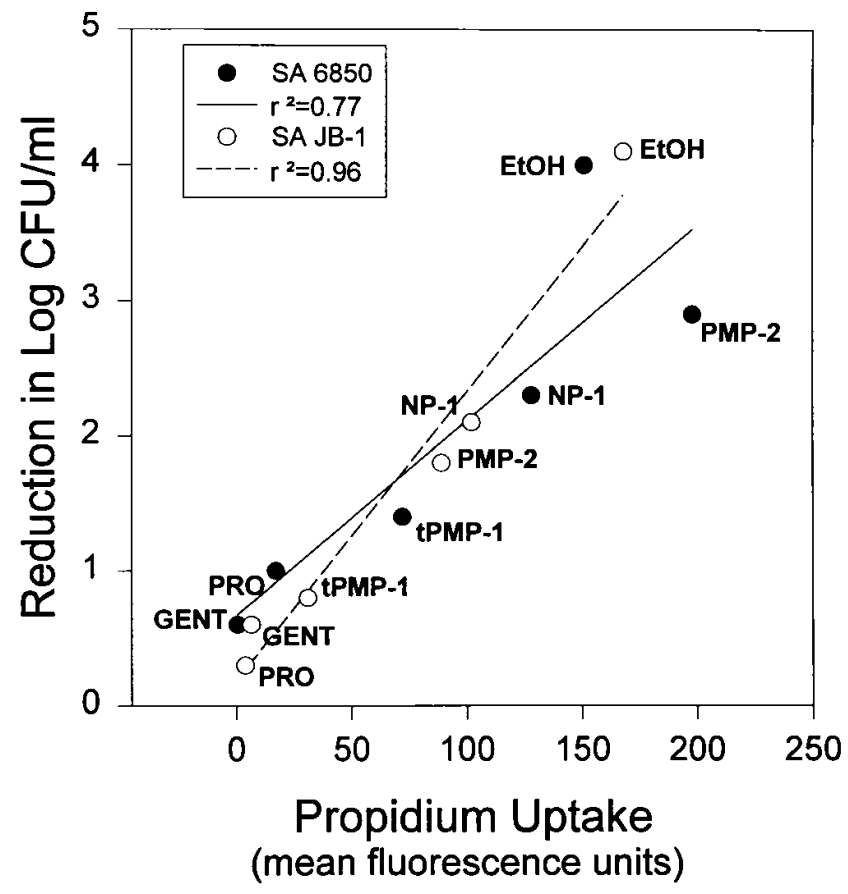

Figure 6. Correlation analysis of the relationship between membrane permeabilization (PI uptake) and cell death (reduction in log CFU/ $\mathrm{ml}$ ). First-order regressions were determined and correlation coefficients $\left(r^{2}\right)$ were calculated from mean results of at least two independent experiments. $95 \%$ confidence intervals were intentionally excluded to improve clarity. 
Table II. Influence of $\Delta \psi$ on the Relationship among Depolarization, Permeabilization, and Viability in S. aureus*

\begin{tabular}{|c|c|c|c|c|c|c|}
\hline \multirow[b]{2}{*}{ Exposure } & \multicolumn{3}{|c|}{ SA 6850} & \multicolumn{3}{|c|}{ SA JB-1 } \\
\hline & $\begin{array}{c}\Delta \mathrm{DiOC}_{5} \\
\text { retention" } \\
(\Delta \psi)\end{array}$ & $\begin{array}{c}\Delta \text { PI uptake } \\
\text { (permeability) }\end{array}$ & $\begin{array}{c}\Delta \mathrm{Log} \text { CFU/ml } \\
\text { (viability) }\end{array}$ & $\begin{array}{c}\Delta \mathrm{DiOC}_{5} \\
\text { retention }(\Delta \psi)\end{array}$ & $\begin{array}{l}\Delta \text { PI uptake } \\
\text { (permeability) }\end{array}$ & $\underset{\text { (viability) }}{\Delta \log C F U / m l}$ \\
\hline $\mathrm{EtOH}$ & $-92.7 \pm 16.3^{\|}$ & $165.9 \pm 18.8^{\|}$ & $-3.8 \pm 1.2^{\|}$ & $-79.9 \pm 12.5^{\|}$ & $173.4 \pm 14.1^{\|}$ & $-4.2 \pm 0.7^{\|}$ \\
\hline PMP-2 & $-129.4 \pm 23.1^{\|}$ & $212.8 \pm 19.2^{\|}$ & $-3.3 \pm 0.8^{\|}$ & $-84.7 \pm 14.0^{\|}$ & $96.6 \pm 8.2^{\| \pi}$ & $-1.6 \pm 0.6^{\|^{\mid \pi}}$ \\
\hline MEN + PMP-2 & $-114.7 \pm 13.9$ & $196.2 \pm 21.6$ & $-2.7 \pm 0.5^{\|}$ & $-102.6 \pm 13.2^{\|}$ & $171.6 \pm 17.1^{\| * *}$ & $-2.5 \pm 0.3^{\| * *}$ \\
\hline tPMP-1 & $24.9 \pm 10.5$ & $142.1 \pm 9.3^{\|}$ & $-1.8 \pm 0.5^{\|}$ & $19.5 \pm 8.9$ & $47.9 \pm 14.6^{\|\| \|}$ & $-0.8 \pm 0.7^{\| \pi}$ \\
\hline MEN + tPMP-1 & $20.7 \pm 8.8$ & $76.3 \pm 4.7^{\|}$ & $-1.8 \pm 1.0$ & $16.4 \pm 11.2$ & $68.2 \pm 10.4^{\| * *}$ & $-1.6 \pm 0.3^{\| * *}$ \\
\hline NP-1 & $-121.8 \pm 27.4$ & $117.3 \pm 13.6$ & $-2.8 \pm 0.4$ & $-93.6 \pm 17.1^{\|}$ & $107.1 \pm 11.2^{\|}$ & $-2.5 \pm 0.5^{\|}$ \\
\hline $\mathrm{MEN}+\mathrm{NP}-1$ & $-105.6 \pm 18.3$ & $111.6 \pm 7.8$ & $-2.6 \pm 0.2$ & $-98.6 \pm 16.6^{\|}$ & $104.4 \pm 8.6^{\|}$ & $-2.3 \pm 0.9^{\|}$ \\
\hline
\end{tabular}

$* \mathrm{MCF}$, minimum $n=2$; PMP-2 exposure performed at $\mathrm{pH} 5.5$; all others performed at $\mathrm{pH} 7.2$ (see text for concentrations). ${ }^{\ddagger} \mathrm{Change}$ in mean channel fluorescence versus control as determined by flow cytometry. ${ }^{\S} \mathrm{Logarithm}_{10} \mathrm{CFU} / \mathrm{ml}$ determined at $60 \mathrm{~min}$ of exposure by quantitative culture; se-

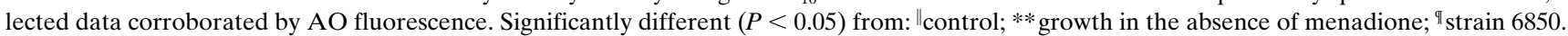

menadione reconstitution did not significantly alter the effects of hNP-1 (at pH 7.2) on depolarization, permeabilization, or viability of strain JB-1 $(P>0.05$; Table II).

PMP-induced membrane permeabilization correlated with staphylococcal cell death. The relationships among antimicrobial agents, depolarization, permeabilization, and cell viability of strain 6850 or JB-1 are summarized in Tables I and II. For PMP-2, tPMP-1, and hNP-1, there was a significant and direct correlation between membrane permeabilization and reduction in cell viability in both strains 6850 and JB- $1\left(r^{2}=0.77\right.$ and 0.96, respectively; Fig. 6). The observation that tPMP-1 did not achieve significant membrane depolarization precluded analysis of correlation between membrane depolarization and cell death among the antimicrobial peptides studied.

\section{Discussion}

tPMP-1 and PMP-2 are small, cationic peptides which originate from rabbit platelets (2). These peptides are structurally similar (mass, charge), but appear likely to be distinct gene products (2). A group of analogous antimicrobial peptides has been isolated recently from human platelets $(3,4)$, suggesting their conservation among mammalian species. Our prior studies suggested that TPMP-1 and PMP-2 target and disrupt the microbial cytoplasmic membrane, resulting in cell death, usually without lysis $(6,17,18)$. Koo et al. found that tPMP-1 staphylocidal activity is enhanced by temperature, solute tonicity, and target cell growth phase associated with increased cell membrane bioenergetics and $\Delta \psi(13)$. Additionally, our previous data suggested that the in vitro staphylocidal activity of tPMP-1 is influenced by, but not exclusively dependent on, target cell $\Delta \psi(12)$. Despite these observations, neither the specific ultrastructural effects of PMPs on bacteria, nor the specific mechanisms by which PMPs exert microbicidal activity had been determined previously.
Neutrophil defensins are perhaps the best studied of the antimicrobial peptides regarding structure and function. Previous evidence indicates that disruption of microbial cytoplasmic membrane energetics and integrity is closely linked to defensin microbicidal action. For instance, human defensins sequentially permeabilize the outer and inner cytoplasmic membranes in Escherichia coli, resulting in cell death (22). Studies using lipid bilayers have shown that defensins cause the formation of ion channels that respond to changes in $\Delta \psi$ (29). These effects, which parallel the bactericidal effects of defensins, are mitigated by proton ionophores (30). In addition, the fungicidal activities of defensins are reduced by inhibitors of mitochondrial function (31). Others have demonstrated that small cationic peptides inhibit cytochrome $c$ activities in bacteria, reducing $\Delta \psi(32-35)$. Moreover, defensins antagonize protein kinase $\mathrm{C}$-mediated signal transduction integral to and regulated by membrane integrity (36). Thus, targeting and perturbation of the microbial cytoplasmic membrane serves as the current model for defensin microbicidal action. Our present findings using flow cytometry similarly show that hNP-1 depolarizes and permeabilizes the staphylococcal membrane, corresponding to cell death.

The ultrastructural studies reported herein indicate that the staphylococcal cell membrane is also a principal target of the microbicidal effects of PMPs. The fact that the cytoplasmic membrane was disrupted in the absence of detectable changes in the cell wall further suggests that PMPs are relatively selective in this regard. Comparable ultrastructural effects have been reported in staphylococci exposed to hNP-1 (27). Thus, PMPs and hNP-1 appear to ultimately lead to similar disruption of staphylococcal cytoplasmic membrane ultrastructure.

However, numerous points of contrast exist between PMPs and hNP-1 with regard to their specific mechanisms of staphylocidal action (Table III). For example, both PMP-2 and tPMP-1 caused increased membrane permeabilization and

Table III. Comparative Effects on Membrane Function Caused by tPMP-1, PMP-2, or hNP-1

\begin{tabular}{lccccc}
\hline Peptide & Mass & Net depolarization & Net permeabilization & Lethality & \multicolumn{1}{c}{ Optimal pH } \\
\hline tPMP-1 & $8.0 \mathrm{kD}$ & No & Yes & Yes & Dependent \\
PMP-2 & $7.7 \mathrm{kD}$ & Yes & Yes & Yes & Dependent \\
hNP-1 & $3.8 \mathrm{kD}$ & Yes & Yes & Yes & Independent \\
\end{tabular}


killing of strain 6850 as compared with JB-1. This finding suggests that the lower $\Delta \psi$ of JB-1 may negatively influence the microbicidal activity of PMPs. In contrast, hNP-1 caused membrane dysfunction and death equally in both strains 6850 and JB-1. This observation indicates hNP-1 activity is independent of $\Delta \psi$ in the range of -100 to $-150 \mathrm{mV}$ exhibited by these test strains. Unlike PMP-2 or hNP-1, it is notable that tPMP-1 failed to depolarize the cytoplasmic membrane of either strain. Recent biophysical evidence further substantiates this hypothesis; in contrast to defensins, tPMP-1 does not appear to form voltage-gated pores in lipid bilayers (18). Furthermore, the $\mathrm{pH}$ optimum for PMP-2 ( $\mathrm{pH}$ 5.5) differs from those of tPMP-1 and hNP-1 (7.2). Collectively, PMP-2, tPMP-1, and hNP-1 appear to differentially exploit target cell $\Delta \psi$ and conditions of $\mathrm{pH}$ via three distinct mechanisms of action leading to microbicidal effects (Table III).

Intact staphylococcal $\Delta \psi$ is related to tPMP-1 and PMP-2 activity, but disruption of $\Delta \psi$ does not appear to be the specific target of their staphylocidal mechanisms. For example, menadione generally increased membrane permeabilization and killing of JB-1 due to PMP-2 and tPMP-1 as compared with JB-1 cultured in the absence of menadione. However, reconstitution of $\Delta \psi$ did not normalize JB-1 membrane permeabilization or killing due to either PMP to levels observed for parental strain 6850. Furthermore, tPMP-1 did not depolarize the cytoplasmic membrane of either $S$. aureus strain grown in the presence of menadione. Therefore, it appears that PMP-2 and hNP-1 kill staphylococci via mechanisms of action that are closely linked to membrane depolarization, while tPMP-1 executes a mechanism of action which does not directly involve membrane depolarization.

Hypothetical models of the mechanisms of action of tPMP-1, PMP-2, and hNP-1 may be formulated based on the current data, viewed in the context of previous observations. First, the influence of $\mathrm{pH}$ on peptide activity could be attributable to an alteration in peptide conformation, altered proton gradient $(\Delta \mathrm{pH})$ influencing net proton motive force and $\Delta \psi$, or both. Nonetheless, tPMP-1 appears to cause membrane permeabilization in the absence of depolarization. This effect is influenced by the inherent $\Delta \psi$ of the target cell and microenvironmental $\mathrm{pH}$, and is associated with microbicidal activity. However, membrane depolarization is not the target of the mechanism of tPMP-1 action, since $\Delta \psi$ is unchanged after exposure to this peptide. This mechanism would imply selective permeabilization of the cell membrane to cation efflux or anion influx, thereby preserving a trans-negative gradient. Alternatively, certain microorganisms may be able to compensate for localized tPMP-1-induced depolarization, concealing a net depolarization. The observed bimodal distributions in permeabilization of 6850 or JB-1 due to tPMP-1, PMP-2, or hNP-1 are suggestive of subpopulations which may differ in membrane energetic status (i.e., cell cycle), or a threshold for permeabilization. This latter effect may represent a threshold for peptide concentration necessary for peptide interaction with the membrane, or reflect heterogeneity of cells within a population which may overcome transient permeabilization.

In contrast to tPMP-1, PMP-2 appears to cause both membrane depolarization and permeabilization leading to staphylococcal death. Furthermore, these effects are influenced by the baseline $\Delta \psi$ of the target cell, as well as exposure $\mathrm{pH}$. Although membrane depolarization due to PMP-2 occurred in both strains, it was enhanced in 6850 versus JB-1, and at pH 5.5 versus $\mathrm{pH}$ 7.2. In addition, reduced depolarization of JB-1 due to PMP-2 corresponded with reduced permeabilization in this strain. These data suggest that the staphylocidal mechanism of PMP-2 integrates depolarization and permeabilization in a manner influenced by target cell $\Delta \psi$.

Finally, hNP-1 causes membrane depolarization and permeabilization which differs from both tPMP-1 and PMP-2 in these strains with $\Delta \psi$ differing by $-50 \mathrm{mV}$. For example, hNP-1 depolarization was equivalent in both the 6850 and JB-1 strains at either $\mathrm{pH} 5.5$ or 7.2. However, permeabilization and killing due to hNP-1 was greater at $\mathrm{pH} 7.2$ than $\mathrm{pH} 5.5$, as was the case for PMP-2. Based on these data, it is reasonable to hypothesize that the threshold $\Delta \psi$ for hNP-1 activity is greater (more positive) than $-100 \mathrm{mV}$. As with tPMP-1, hNP-1 produced a bimodal distribution in permeabilization, suggestive of a threshold for peptide concentration or $\Delta \psi$ needed for membrane disruption reflected by a heterogeneous population.

Our present data suggest that tPMP-1 and PMP-2 also exhibit similarities and differences in mechanism of action with cationic microbicidal peptides other than hNP-1. For example, Pep 5 (37), nisin (38), melittin (39), colicins (e.g., E1, Ia, Ib, A, $\mathrm{K}$, and V) $(40,41)$, and tachyplesin I (42) target the bacterial membrane to form ion-permeable channels which lead to membrane depolarization. The majority of these peptides require a threshold $\Delta \psi$, and appear to achieve membrane depolarization and eventual permeabilization. Thus, our current findings suggest that tPMP-1 and PMP-2 exhibit specific mechanisms of action which differ from many other antimicrobial peptides (e.g., tPMP-1 does not depolarize the staphylococcal membrane). Overall, these differences may reflect diversity in mechanisms of action of antimicrobial peptides which share structural similarities.

In light of the growing interest in the potential use of antimicrobial peptides as therapeutic agents, it is becoming increasingly important to differentiate their mechanisms of microbicidal activity versus host cell toxicity. PMPs may be unique among endogenous antimicrobial peptides in their intended release from host cells in response to physiologic agonists. The fact that PMPs are released from platelets stimulated with agonists generated in the setting of infection $(1,2$, 10) underscores the likelihood that PMPs possess inherent structural features which minimize their toxicity to host tissues. In contrast, most antimicrobial peptides in mammals are either secreted onto epithelial surfaces (e.g., cryptdins, tracheal antimicrobial peptide) or contained within immune effector cells (e.g., neutrophil defensins). For instance, defensin release from neutrophil granules has been linked to host cell toxicity (29-31). Defining the specific mechanisms of action of antimicrobial peptides such as PMPs will advance our understanding of the relationship between their structure and function. A greater awareness of the diversity and specificity of these molecules may ultimately prove useful in designing new agents with novel mechanisms of action or synergistic activities which circumvent conventional microbial antibiotic resistance, and exert minimal mammalian cell toxicity.

\section{Acknowledgments}

We appreciate the collaborative insights of Tai Wu (University of California, Davis, CA) and Dr. Cindy Nast (Cedars Sinai Medical Center, Los Angeles, CA), and the superior technical skills of Robert M. Dietz, Alexander J. Shen (George Washington School of Medi- 
cine, Washington, DC), and Anne Cotleur (Veterans Administration Medical Center, San Francisco, CA).

These investigations were supported in part by grants from the National Institutes of Health (AI 39001-01 and AI39108-01 to M.R. Yeaman, AI 39108-01 to A.S. Bayer, and AI-32506-04 to P.M. Sullam), and the American Heart Association (National AHA-95-01260 to M.R. Yeaman and California AHA 95-235 to P.M. Sullam).

\section{References}

1. Yeaman, M.R., S.M. Puentes, D.C. Norman, and A.S. Bayer. 1992. Partial purification and staphylocidal activity of thrombin-induced platelet microbicidal protein. Infect. Immun. 60:1202-1209.

2. Yeaman, M.R., Y.-Q. Tang, A.J. Shen, A.S. Bayer, and M.E. Selsted. 1997. Purification and in vitro activities of rabbit platelet microbicidal proteins. Infect. Immun. 65:1023-1031.

3. Tang, Y.Q., M.R. Yeaman, and M.E. Selsted. 1995. Purification, characterization, and antimicrobial properties of peptides released from thrombininduced human platelets. Blood. 86:910a. (Abstr. 3626)

4. Tang, Y.Q., M.R. Yeaman, and M.E. Selsted. 1995. Microbicidal and synergistic activities of human platelet factor-4 (hPF-4) and connective tissue activating peptide-3 (CTAP-3). Blood. 86:556a. (Abstr. 2212)

5. Wu, T., M.R. Yeaman, and A.S. Bayer. 1994. In vitro resistance to platelet microbicidal protein correlates with endocarditis source among staphylococcal isolates. Antimicrob. Agents Chemother. 38:729-732.

6. Yeaman, M.R., A. Ibrahim, S.G. Filler, A.S. Bayer, J.E. Edwards, and M.A. Ghannoum. 1993. Thrombin-induced rabbit platelet microbicidal protein is fungicidal in vitro. Antimicrob. Agents Chemother. 37:546-553.

7. Drake, T.A., and M. Pang. 1988. Staphylococcus aureus induces tissue factor expression in cultured human cardiac valve endothelium. J. Infect. Dis. 157:749-756

8. Drake, T.A., and M. Pang. 1989. Effects of interleukin-1, lipopolysaccharide, and streptococci on procoagulant activity of cultured human cardiac valve endothelial and stromal cells. Infect. Immun. 57:507-512.

9. Bancsi, M.J.L.M.F., J. Thompson, and R.M. Bertina. 1994. Stimulation of monocyte tissue factor expression in an in vitro model of bacterial endocarditis. Infect. Immun. 62:5669-5672.

10. Azizi, N., C. Li, A.J. Shen, A.S. Bayer, and M.R Yeaman. 1996. Staphylococcus aureus elicits release of platelet microbicidal proteins in vitro. Abstract 866. 36th Interscience Conference on Antimicrobial Agents and Chemotherapy, New Orleans, LA.

11. Bayer, A.S., M.D. Ramos, B.E. Menzies, M.R. Yeaman, A. Shen, and A.L. Cheung. 1997. Hyperproduction of $\alpha$-toxin by Staphylococcus aureus results in paradoxically-reduced virulence in experimental endocarditis: a host defense role for platelet microbicidal proteins. Infect. Immun. 65:4652-4660.

12. Koo, S.P., A.S. Bayer, H.G. Sahl, R.A. Proctor, and M.R. Yeaman. 1996. Staphylocidal action of thrombin-induced platelet microbicidal protein is not solely dependent on transmembrane potential. Infect. Immun. 64:10701074 .

13. Koo, S.P., M.R. Yeaman, and A.S. Bayer. 1996. Staphylocidal action of thrombin-induced platelet microbicidal protein is influenced by microenvironment and target cell growth phase. Infect. Immun. 64:3758-3764.

14. Sullam, P.M., U. Frank, M.G. Tauber, M.R. Yeaman, A.S. Bayer, and H.F. Chambers. 1993. Effect of thrombocytopenia on the early course of streptococcal endocarditis. J. Infect. Dis. 168:910-914.

15. Dhawan, V.K., M.R. Yeaman, A.L. Cheung, E. Kim, P.M. Sullam, and A.S. Bayer. 1997. Phenotypic resistance to thrombin-induced platelet microbicidal protein in vitro is correlated with enhanced virulence in experimental endocarditis due to Staphylococcus aureus. Infect. Immun. 65:3292-3299.

16. Yeaman, M.R., S.S. Soldan, M.A. Ghannoum, J.E. Edwards, Jr., S.G. Filler, and A.S. Bayer. 1996. Resistance to platelet microbicidal protein (PMP) results in increased severity of experimental Candida albicans endocarditis. Infect. Immun. 64:1379-1384.

17. Wu, T.M., M.R. Yeaman, C. Nast, C. Itatani, and A.S. Bayer. 1996. Ultrastructural evidence that platelet microbicidal protein (PMP) targets the bacterial cell membrane. Abstract A72. 96th General Meeting of the American Society for Microbiology, New Orleans, LA.
18. Koo, S.P., M.R. Yeaman, and A.S. Bayer. 1997. Cell membrane is a principal target for the staphylocidal action of platelet microbicidal protein. Infect. Immun. 65:4795-4800.

19. Balwit, J.M., P. van Langevelde, J.M. Vann, and R.A. Proctor. 1994. Gentamicin-resistant menadione and hemin auxotrophic Staphylococcus aureus persist within cultured endothelial cells. J. Infect. Dis. 170:1033-1037.

20. Selsted, M.E. 1993. Investigational approaches for studying the structures and biologic functions of myeloid antimicrobial peptides. Gen. Engineering. 15:131-147.

21. Harwig, S.S.L., T. Ganz, and R.I. Lehrer. 1994. Neutrophil defensins: purification, characterization, and antimicrobial testing. Methods Enzymol. 236: $160-176$.

22. Lehrer, R.I., A. Barton, and T. Ganz. 1988. Concurrent assessment of inner and outer membrane permeabilization and bacteriolysis in E. coli by multiple wavelength spectrometry. J. Immunol. Methods. 108:153-158.

23. Vaara, M., and T. Vaara. 1983. Polycations sensitize enteric bacteria to antibiotics. Antimicrob. Agents Chemother. 24:107-113.

24. Pratt, W.B., and R. Fekety. 1986. Bactericidal inhibitors of protein synthesis. In The Antimicrobial Drugs. Oxford University Press, New York. 153183.

25. Shapiro, H.M. 1990. Cell membrane potential analysis. Methods Enzymol. 33:25-35.

26. Darzynkiewicz, Z., X. Li, and J. Gong. 1994. Assays of cell viability: discrimination of cells dying of apoptosis. Methods Cell Biol. 41:15-38.

27. Shimoda, M., K. Ohki, Y. Shimamoto, and O. Kohashi. 1995. Morphology of defensin-treated Staphylococcus aureus. Infect. Immun. 63:2886-2891.

28. Traganos, F., and Z. Darzynkiewicz. 1994. Lysosomal proton pump activity: supravital cell staining with acridine orange differentiates leukocytes subpopulations. Methods Cell Biol. 41:185-194.

29. Kagan, B.L., M.E. Selsted, T. Ganz, and R.I. Lehrer. 1990. Antimicrobial defensin peptides form voltage-dependent ion-permeable channels in planar lipid bilayer membranes. Proc. Natl. Acad. Sci. USA. 87:210-214.

30. Ganz, T., M.E. Selsted, and R.I. Lehrer. 1990. Defensins. Eur. J. Haematol. 44:1-8.

31. Lehrer, R.I., T. Ganz, and M.E. Selsted. 1990. Defensins: natural peptide antibiotics from neutrophils. ASM News. 56:315-318.

32. Carroll, S.F., and R.F. Martinez. 1981. Antibacterial peptide from normal rabbit serum. III. Inhibition of microbial electron transport. Biochemistry. 20:5988-5994.

33. Davies, K.A., Y. Hatefi, F.R. Salemme, and M.D. Kamen. 1972. Enzymic redox reactions of cytochromes c. Biochem. Biophys. Res. Commun. 49: 1329-1335.

34. Person, P., H. Zipper, A.S. Fine, and P.T. Mora. 1964. Macroion interactions involving cytochrome system components. J. Biol. Chem. 239:4159-4162.

35. Smith, L., H.C. Davies, and M.E. Nava. 1976. Evidence for binding sites on cytochrome $c$ for oxidases and reductases from studies of different cytochromes $c$ of known structure. Biochemistry. 15:5827-5831.

36. Charp, P.A., W.G. Rice, R.L. Raynor, E. Reimund, J.M. Kinkade, T. Ganz, M.E. Selsted, R.I. Lehrer, and J.F. Kuo. 1988. Inhibition of protein kinase $\mathrm{C}$ by defensins, antibiotic peptides from human neutrophils. Biochem. Pharmacol. 37:951-956.

37. Kordel, M., R. Benz, and H.G. Sahl. 1988. Mode of action of the staphylococcin-like peptide Pep-5: voltage-dependent depolarization of bacterial and artificial membranes. J. Bacteriol. 170:84-88.

38. Ruhr, E., and H.G. Sahl. 1985. Mode of action of the peptide antibiotic nisin and influence on the membrane potential of whole cells and on cytoplasmic and artificial membrane vesicles. Antimicrob. Agents Chemother. 27:841845 .

39. Kempf, C., R. Klausner, J.N. Weinstein, J. van Renswoude, M. Pincus, and R. Blumenthal. 1982. Voltage-dependent transbilayer orientation of melittin. J. Biol. Chem. 257:2469-2476.

40. Konisky, J. 1982. Colicins and other bacteriocins with established modes of action. Annu. Rev. Microbiol. 36:125-144.

41. Yang, C.C., and J. Konisky. 1984. Colicin V-treated Escherichia coli does not generate membrane potential. J. Bacteriol. 158:757-759.

42. Ohta, M., H. Ito, K. Masuda, S. Tanaka, Y. Arakawa, R. Wacharotayankun, and N. Kato. 1992. Mechanisms of antibacterial action of tachyplesins and polyphemusins, a group of antimicrobial peptides isolated from horseshoe crab hemocytes. Antimicrob. Agents Chemother. 36:1460-1465. 